\title{
The Microstructure and Properties of Laser Shock Peened CMSX4 Superalloy
}

\author{
MAGDALENA ROZMUS-GÓRNIKOWSKA, JAN KUSIŃSKI, ŁUKASZ CIENIEK, \\ and JERZY MORGIEL
}

The influence of laser shock peening on the surface morphology and microstructure of single-crystal CMSX4 nickel-based superalloy was investigated by optical profilometry and atomic force microscopy, scanning and transmission electron microscopy as well as scanning-transmission electron microscopy in high-angle annular dark-field mode. Maps of chemical elements distribution in the laser-affected areas were determined using energy-dispersive X-ray spectroscopy. Furthermore, after the LSP, nanohardness tests were conducted on the cross section of the treated samples as well as the untreated material. Laser shock peening caused an ablation and melting of the surface layer and hence enlarged the surface roughness. Beneath the surface, in the laser shock-peened areas, severe distortion of the regular $\gamma / \gamma^{\prime}$ microstructure was observed. In the surface layer, down to about $15 \mu \mathrm{m}$, shear bands of localized deformation were formed. Moreover, the result showed that the average nano-hardness value was obviously increased in the laser-treated region.

https://doi.org/10.1007/s11661-021-06277-7

(c) The Author(s) 2021

\section{INTRODUCTION}

CMSX4 is a second-generation Ni-base single-crystal superalloy, which is used to make blades for gas turbines in aero-engines and power plants. Chemical composition of CMSX-4 superalloy contains more than ten elements and is especially designed to achieve an around 70 pct volume fraction of $\gamma^{\prime}$ phase. ${ }^{[1,2]}$ Its microstructure in the annealed state consists of cuboidal precipitates of $\gamma^{\prime}$ phase $\left(\mathrm{Ni}_{3} \mathrm{Al}\right.$-based), coherent with a $\gamma$ solid solution matrix. ${ }^{[3,4]}$

Turbine blades are subjected to high loads at high temperatures during operation; they must possess good structural quality and high strength. Laser shock peening (LSP) is an innovative surface treatment which can be used in the power generation industry to improve the fatigue life of the components. ${ }^{[5,6]}$ Laser shock peening, also known as laser shock processing, is a process of material surface layer strengthening by means of high-intensity pico- and nanosecond laser pulses. It modifies the surfaces of metallic materials and induces a

MAGDALENA ROZMUS-GÓRNIKOWSKA, JAN KUSIŃSKI, and LUKASZ CIENIEK are with the AGH University of Science and Technology, Faculty of Metals Engineering and Industrial Computer Science, al. Mickiewicza 30, 30-059 Kraków, Poland. Contact e-mail: rozmus@agh.edu.pl JERZY MORGIEL is with the Institute of Metallurgy and Materials Science Polish Academy of Sciences, 25 Reymonta street, 30-059 Kraków, Poland.

Manuscript submitted September 18, 2020, accepted March 26, 2021.

Article published online April 28, 2021 compressive residual stress state into the surface layer of the component. ${ }^{[7,8]}$ Compared to other surface treatments, LSP has unique advantages of controllable energy and small heat distortion of the treated parts. ${ }^{[9,10]}$

Before the laser shock processing, the material is covered by a sacrificial ablating layer to prevent the surface from damage during the treatment. This layer, as a black adhesive film or a metal foil, which is opaque to the laser radiation, strongly absorbs it. When the laser pulse strikes the sample, the absorbing layer and a thin metal surface layer are instantly vaporized. Due to vapor ionization and heating by laser energy absorption, plasma is formed.$^{[11,12]}$ Thus, the plasma is created in the sacrificial opaque layer with detrimental effects such as thermal effects and ablation. Moreover, during the process, the material is covered by a transparent, inert tamping overlay (for example, a thin layer of flowing water). The transparent to laser light water layer limits free plasma expansion over the sample surface. This plasma confinement generates high pressures and shock waves, which propagate into the bulk and generate compressive stresses. ${ }^{[1,12]}$ Generation of the compressive stresses in the surface layer improves the fatigue life, which is very important, i.e., for turbine blades of aircraft engines. ${ }^{[13]}$ When these stresses reach the yield strength of the treated metal, plastic deformation occurs. Moreover, the surface layer properties would change greatly, affected by a high temperature, in a wide range from the ambient or close to the critical temperature, which may accompany the LSP. Numerous metals and alloys have been successfully laser peened, 
including titanium alloys, steels and aluminum alloys. ${ }^{[14-18]}$ Most papers describe increases in hardness, dislocation density, compressive stresses, surface roughness, corrosive resistance, and so on. However, a limited number of studies have been carried out to understand the influence of LSP on the microstructure and properties of nickel superalloys, especially for single-crystal superalloys. ${ }^{[19,20]}$ In this alloy, the elimination of grain boundaries leads to improved creep properties, typical damage mechanisms on high-pressure turbines. ${ }^{[21]}$ The microstructure of CMSX-4 superalloy has been extensively studied, ${ }^{[2,23]}$ but there is a lack of detailed TEM microstructure investigations on this type of alloy after LSP treatment. It is worth mentioning that characterization of the near-surface regions of the material after LSP is important for understanding the fundamental microstructural changes introduced by this surface treatment. Therefore, the aim of this contribution is to investigate the surface morphology and roughness, microstructure and nanohardness of the CMSX-4 nickel alloy subsurface layer after LSP.

\section{MATERIALS AND EXPERIMENTAL PROCEDURES}

The investigation has been performed using CMSX4 superalloy delivered by Howmet Ltd, UK, in the form of a $\langle 001\rangle$ oriented bar. Specimens for LSP experiments were cut parallel to $\{001\}$ planes from the bar. The chemical composition of the alloy is (in wt pet): Ni-9.5Co-6.4Cr-6.4Ta-6.4W-5.6Al-2.9Re-1Ti-0.6-

Mo-0.1Hf. Samples were received after standard heat treatment: solid solution annealing at $1280{ }^{\circ} \mathrm{C}$ to $1305{ }^{\circ} \mathrm{C}$ for 6 hours followed by the aging at $1140{ }^{\circ} \mathrm{C}$ for 4 hours and at $870{ }^{\circ} \mathrm{C}$ for 16 hours.

Prior to LSP, sample surfaces were ground with $\mathrm{SiC}$ sandpapers with grit of 500 to 4000 and then polished to make the average surface roughness $R$ a $100 \mathrm{~nm}$. The polished sample surfaces were etched before the laser shock processing, so after treatment the surface microstructure, unchanged by additional post-processing metallographic preparation, could be examined. The etching was carried out in two stages: in a solution of 24 $\mathrm{mL} \mathrm{C}_{2} \mathrm{H}_{5} \mathrm{OH}, 25 \mathrm{~mL} \mathrm{HNO}_{3}$ and $27 \mathrm{~mL} \mathrm{HCL}$ followed by etching with a solution of $4 \mathrm{~g} \mathrm{CuSO}_{4}, 20 \mathrm{~mL} \mathrm{HCL}$ and $20 \mathrm{~mL} \mathrm{C}_{2} \mathrm{H}_{5} \mathrm{OH}$. Before laser treatment, the etched surfaces were coated with black paint as a laser energy absorbing layer and then immersed in flowing water with a thickness of $\sim 1 \mathrm{~mm}$. LSP experiments were performed using a $1 \mathrm{~J}$ Q-switched Nd:YAG laser (Q-switched Powerlite Precision II 9010 DLS) operating in the 1064-nm wavelength range (first harmonic) and at a frequency of $10 \mathrm{~Hz}$ and pulse duration of $18 \mathrm{~ns}$. During LSP, the samples were treated by a series of single laser shots. The diameter of the laser beam on the target was $2 \mathrm{~mm}$ and the laser energy density $\sim 13.2 \mathrm{~J} /$ $\mathrm{cm}^{2}$. After LSP, the remaining black paint coating was stripped off with acetone. Surface microstructure and cross sections before and after laser treatment were examined by scanning electron microscopy (SEM, Hitachi S-3500 N, FEI Nova NanoSEM 450). TEM and plain view examinations were carried out on thin foil specimens obtained from $\sim 0.5 \mathrm{~mm}$ slices cut parallel to the laser-treated surface and ground down from the core side to about $0.1 \mathrm{~mm}$. The $3-\mathrm{mm}$ discs were punched from these slices. The disk centers were then dimpled down, from the core side, to 30 to $50 \mu \mathrm{m}$ and electropolished, using a Struers Tenupol-2 double-jet electropolishing unit, and a $450 \mathrm{~mL} \mathrm{CH}{ }_{3} \mathrm{COOH}+100$ $\mathrm{mL} \mathrm{HClO}_{4}+450 \mathrm{~mL} \mathrm{CH} \mathrm{OHCH}_{2} \mathrm{OC}_{4} \mathrm{H}_{9}$ electrolyte, to make them suitable for STEM and TEM observations. Moreover, TEM lamellas were excised perpendicular to the treated surface by means of a focused ion beam (FIB) using an FEI Quanta 3D 200 Dual Beam Focused Ion Beam instrument. The microstructure observations were performed with Philips CM20, Tecnai G2 F20 and Jeol 200CX transmission microscopes.

Maps of chemical element distribution in the nano areas were determined using energy-dispersive X-ray spectroscopy. Morphology of the laser-treated surfaces was examined by atomic force microscopy (AFM, Veeco Dimension ${ }^{\circledR}$ Icon $^{\top M}$ SPM). Surface roughness, before and after LSP, was examined by interferometry (Veeco Wyko NT 9300 profilometer). All measurements of surface roughness were performed three times in each region, and the average values are reported.

Moreover, after the LSP treatment, nanohardness tests were conducted on the cross sections of the treated sample surfaces as well as the untreated material. Nanoindentation tests were performed using nanoindenter NHT 50-183 instruments equipped with a Berkovich diamond indenter. Tests included cross-sectioned measurements with a step size of $5 \mu \mathrm{m}$, along the line perpendicular to the surface treated by LSP. A load of $15 \mathrm{mN}$ was applied for each indentation.

\section{RESULTS AND DISCUSSION}

\section{A. SEM, AFM and Interferometry Examinations}

Figure 1 is a SEM image showing the microstructure of CMSX-4 superalloy before laser treatment. The cuboidal $\gamma^{\prime}$ precipitates surrounded by channels of $\gamma$

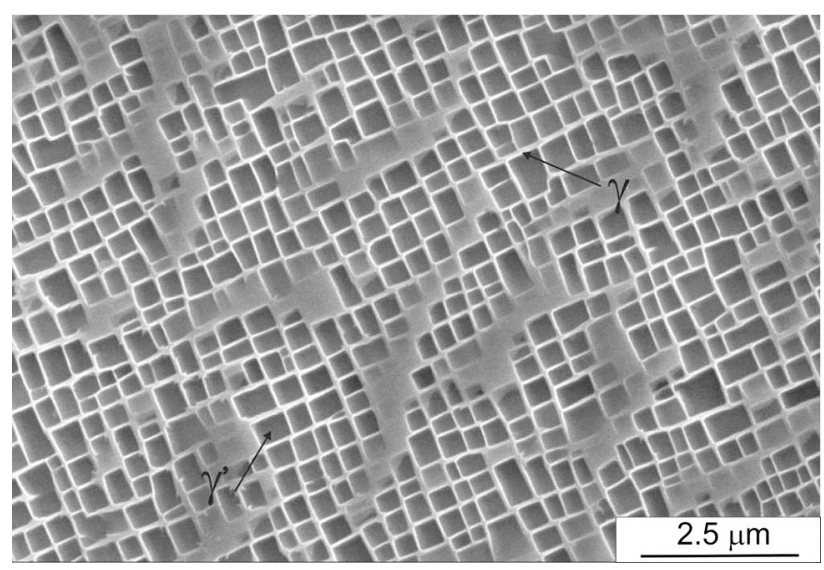

Fig. 1-SEM image showing the microstructure of CMSX4 alloy before laser treatment. 
phase are marked with arrows. According to the literature, the cuboidal precipitates of $\gamma^{\prime}$ phase $\left(\mathrm{Ni}_{3} \mathrm{Al}\right.$-based) are coherent with the $\gamma$ phase matrix (Ni-based solid solution). ${ }^{[1,2]}$ Figure 2(a) shows a SEM image of a sample surface with four laser-shocked areas (indicated with arrows), with a sufficiently large distance between their centers, i.e., so that the laser spots do not overlap. Figure 2(b) shows the structure at a higher magnification of the area marked in Figure 2(a). The numbers I-IV are designated in the following order: I, the melted area; II, the area of the $\gamma / \gamma^{\prime}$ interface melting; III, the deformed material area (without remelting); IV, the initial material 1.

Although a black coating was applied before the LSP treatment, as an opaque target to the laser beam, a material melting at the sample surface was observed in the central area of the spots. According to the literature data, ${ }^{[2]}$ the carbon plasma temperature in the early phase of expansion, near the surface, determined using optical emission spectroscopy, exceeds 8000 K. Since the black coating also contains carbon particles, it is possible that during the interaction with the laser beam the target is heated to a temperature exceeding its boiling point and also its critical temperature. Indeed, this may explain the sample surface melting in our experiments. In case of CMSX-4 alloy, its liquidus temperature is $1669 \mathrm{~K}$, which is much lower than the sample surface temperature in contact with the plasma plume. Moreover, Moscicki ${ }^{[25]}$ showed that, at the laser fluence of $10 \mathrm{~J} / \mathrm{cm}^{2}$ and wavelength $1064 \mathrm{~nm}$, the maximum surface temperature at the beam center, during ablation of tungsten and boron, enriches 11,700 $\mathrm{K}$ and $>10,000 \mathrm{~K}$ adequately. Also, Tan et al. ${ }^{[26]}$ showed that the Al surface temperature during laser ablation reaches $>8000 \mathrm{~K}$. Since for Ni (main superalloy component) the boiling point is $3186.15 \mathrm{~K}$ and critical temperature $8000 \mathrm{~K},{ }^{[2]]}$ one may expect even some evaporation of the thin surface layer. Thorslund et $a l{ }^{[28]}$ applying a developed mathematical model show that the surface temperature of LSP 304 steel (14,500 K) exceeds its boiling temperature $(3000 \mathrm{~K})$. If surface melting occurs in the central area of a laser-shocked spot, a part of the melted material is explosively ejected as the liquid forming splashes (spreading in all directions from the central zone), which resolidifies on the sample surface (see Figure 2(d)).

Figures 2(c) and (d) shows the microstructure at higher magnification in areas II and III. In Figure 2(c), the deformed areas are indicated with ellipses. The areas in which the alloy melting starts at the $\gamma / \gamma^{\prime}$ interfaces are marked with circles in Figure 2(d). Distortion of the regular $\gamma / \gamma^{\prime}$ cell structure, as compared to initial alloy structure (Figure 1), is observed in the peripheral area (III) of the laser-shocked spot. It should be noted that before the LSP (Figure 1), $\gamma^{\prime}$ phase (gray region) and $\gamma$ phase (bright region) can be observed with clear and sharp interfaces, as shown also in Figure 2(b) (in area IV) and Figure 2(c) (in the lower left corner). Blurred
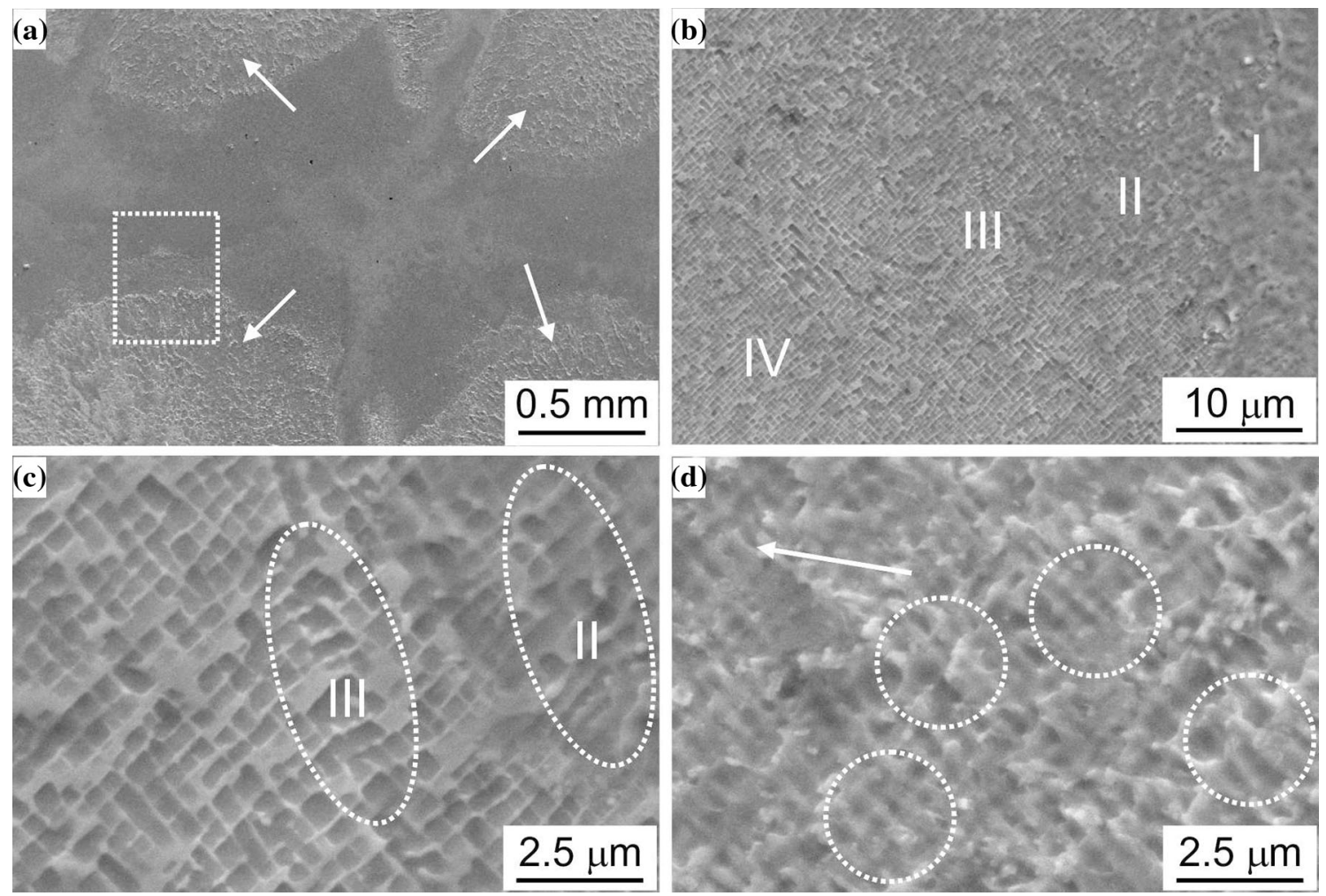

Fig. 2-SEM images show the surface morphology of the CMSX4 alloy after LSP. Arrows in $(a)$ indicate laser-shocked spots, while numbers in (b) mean: I, melted area; II, area of the $\gamma / \gamma^{\prime}$ interphase melting; III, deformed material area (without remelting); IV, initial material; (c) is the magnified image of areas II and III in (b); (d) typical SEM image of the area where the $\gamma / \gamma^{\prime}$ phase interphase melting was observed (arrow shows the direction in which plasma spread, while circles indicate melted phase interphases). 


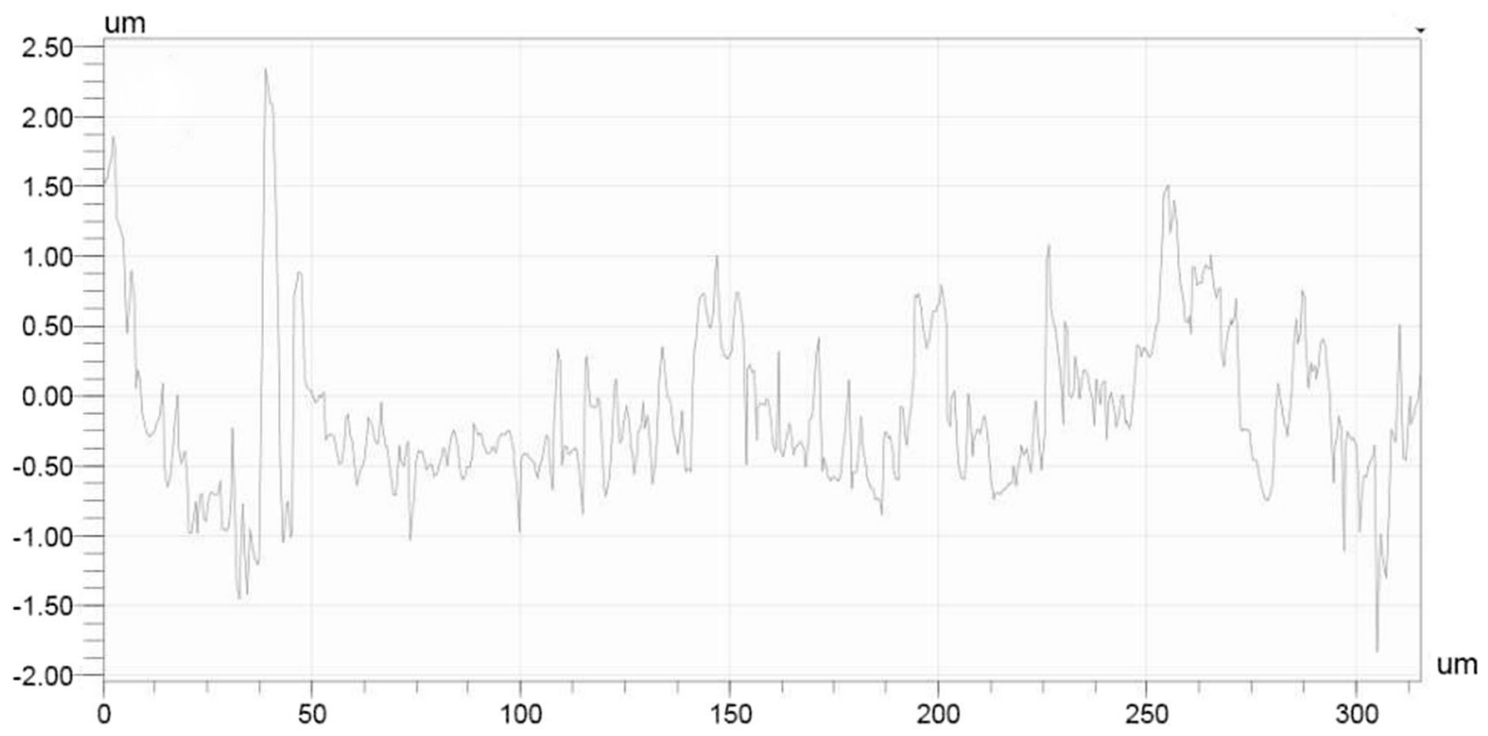

(a)

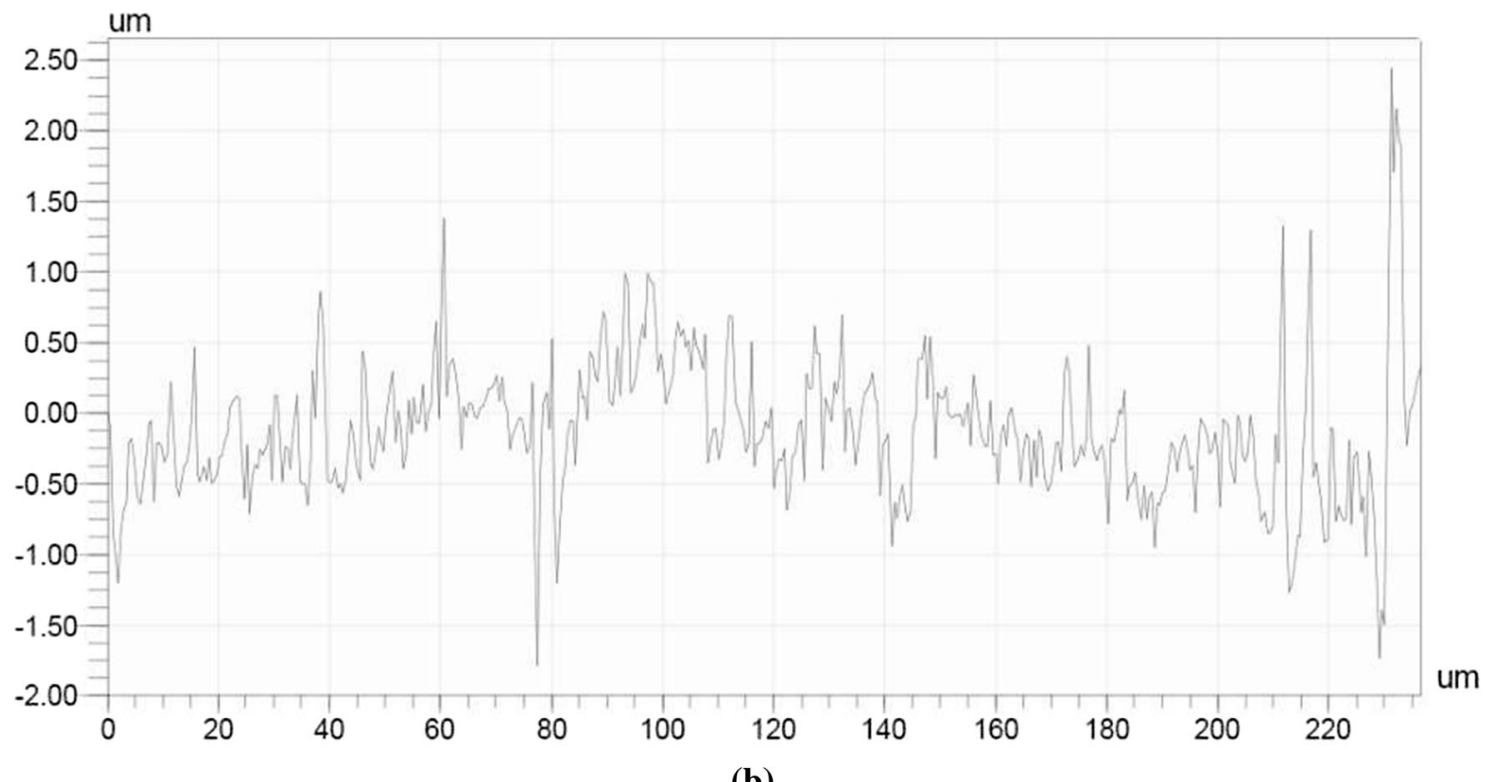

(b)

Fig. 3-Profiles of surface roughness after laser treatment measured along two perpendicular lines [horizontal $(a)$ and vertical $(b)$ ] passing through the laser spot (optical profilometer).

$\gamma / \gamma^{\prime}$ interfaces are observed in Figure 2(c) (circulated area in the top right corner) and in Figure 2(d). This could be caused by the melting at the $\gamma / \gamma^{\prime}$ interfaces. The temperature in the ring area, lying $\sim 0.8$ to $1.3 \mathrm{~mm}$ from the spot center, is lower than the alloy melting point, 1654.5 $\mathrm{K} \pm 4 \mathrm{~K},{ }^{[29]}$ but higher than the $\gamma^{\prime}$ solvus temperature. According to Reference 29 the $\gamma^{\prime}$ precipitates dissolve during heating in a wide temperature range between $1523 \mathrm{~K}$ and $1623 \mathrm{~K}$, depending on the heating rate, adequately $1{ }^{\circ} \mathrm{C}$ to $10^{\circ} \mathrm{C} / \mathrm{min}$. Taking into account a laser heating rate of $\sim 10^{8} \mathrm{~K} / \mathrm{s},{ }^{[30,31]}$ the $\gamma^{\prime}$ phase could not dissolve in solid state below the alloy melting point. Indeed, in this zone $\gamma^{\prime}$ phase remelting begins in areas of the increased energy state, i.e., at the $\gamma / \gamma^{\prime}$ interfaces. This is probably why the interfaces look blurred in the SEM images (in Figures 2(c) and (d)). The consequence of surface melting and spreading of a portion of the melted material - which resolidified on the sample surface - is an increase in the roughness of the surface. The surface morphology of a sample before and after treatment was characterized using an optical profilometer. The example of the surface profiles after the LSP process measured along two perpendicular lines is shown in Figure 3. It was found that both $R \mathrm{a}$ and $R \mathrm{z}$, originally estimated at 10 and $100 \mathrm{~nm}$, increase because of the LSP to $460 \mathrm{~nm}$ and $11.4 \mu \mathrm{m}$, respectively. A representative shear band, visible on the surface in the laser shock-peened area, is shown in the AFM 


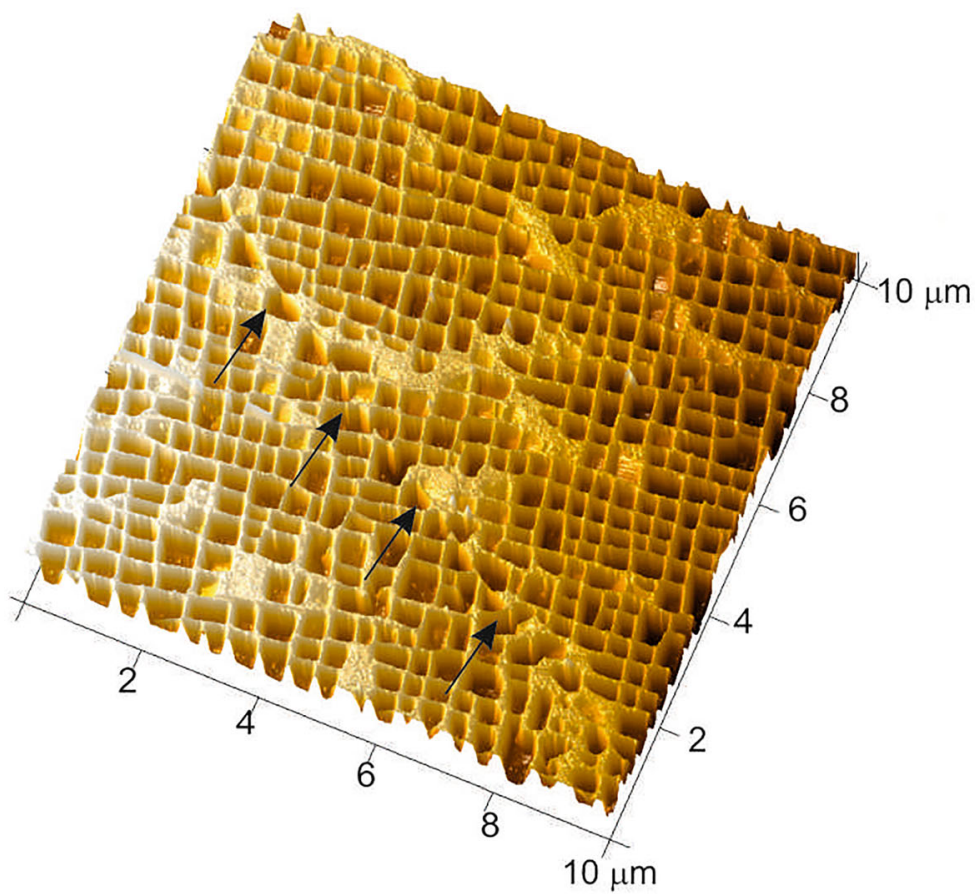

Fig. 4-Typical AFM micrograph of shear bands (arrowed) in CMSX4 alloy after LSP process.

micrograph (Figure 4). This AFM micrograph was taken from the peripheral area of the laser-shocked spot.

The cross-sectional observations were performed to understand the modifications of the sub-surface layer caused by the applied LSP. Structural changes in the surface layer may be considered a result of the simultaneous interaction of the temperature gradient and compressive stresses involved during LSP. Significant microstructure modifications in the surface layer of the shock-peened samples were observed in comparison to the core as well as to a reference sample (see Figure 1). The SEM images in Figures 5(a) through (e) show, in the plane perpendicular to the treated surface, the microstructure of the surface layer formed in different areas of the laser-shocked spot. Figure 5(a) was recorded about 200 to $300 \mu \mathrm{m}$ from the spot center, while Figures 5(b) through (d) was taken on the peripheral parts of the melted area $(\sim 600$ to $700 \mu \mathrm{m}$ from the spot center). In general, depending on the examined spot area subjected to the LSP impact, the surface layer consists of three (Figure 5(a)) or two zones (Figures 5(b) through (d)). Numbers in Figure 5 indicate: (1) the recrystallized zone, (2) heavily deformed zone, (3) deformed zone (with narrow $\gamma$ phase channels in the vicinity of the slip bands) and (4) matrix (not affected by LSP). Figure 5(a) shows a typical SEM microstructure in the area close to the spot center, where surface melting occurred (see Figure 2). In this case, we can distinguish three zones. The first, the subsurface melted zone, is approximately 0.3 to $0.5 \mu \mathrm{m}$ thick. This zone is created as a result of partial material melting and probably a chemical reaction with plasma. The second, recrystallized zone (1), lies under the melted zone (about $2 \mu \mathrm{m}$ thick) and comprises the zone of material which was heavily deformed and recrystallized because of the high temperature (details are presented in the TEM section). The orientation preference occurs as a result of unidirectional forces deforming the material. The third zone ( 2 and 3 ) comprises the zone of deformed material with many deformation bands, reaching from 12 to 15 $\mu \mathrm{m}$. This is characterized by its preferentially oriented fibrous structure (2, below the recrystallized zone) and material area with a structure close to the original one, with the presence of slip bands (3, closer to the core material). The crystals' flattening and elongation are due to the action of forces accompanying the LSP. Also, under the impact of the high LSP pressure, $\gamma^{\prime}$ phase, initially cuboidal or rectangular (see Figure 1), assumes a rhombohedral (diamond-like) shape.

In Figures 5(b) through (d), the microstructure of the peripherals of the laser-shocked spot is shown. The surface layer consists of two different zones, recrystallized (1) and deformed (2 and 3), with only signs of melting (arrowed in Figure 5(b) and as splashes in Figure 5(c)). As the distance from the center of the spot increases, the thickness of the recrystallized zone decreases, respectively (Figures 5(b) to (d)). The thickness of the recrystallized zone is gradually reduced from $\sim 1 \mu \mathrm{m}$ to 100 to $200 \mathrm{~nm}$ with the distance from the center of the spot. This is probably due to both the lower temperature and level of stresses generated at the spot peripherals. Below this ultrathin recrystallized zone (1), there is a zone of deformed material with numerous shear bands (2 and 3). Figure 5(e) is a magnified image of the region marked by the rectangle in Figure 5(d). The areas denoted by circles at the shear bands show $\gamma$ phase displacement of about $150 \mathrm{~nm}$, which proves quite severe alloy deformation caused by LSP. As Lu et al. ${ }^{[32]}$ showed during laser shock peening, the $\gamma^{\prime}$ precipitates deform by lateral expansion (parallel to the sample 

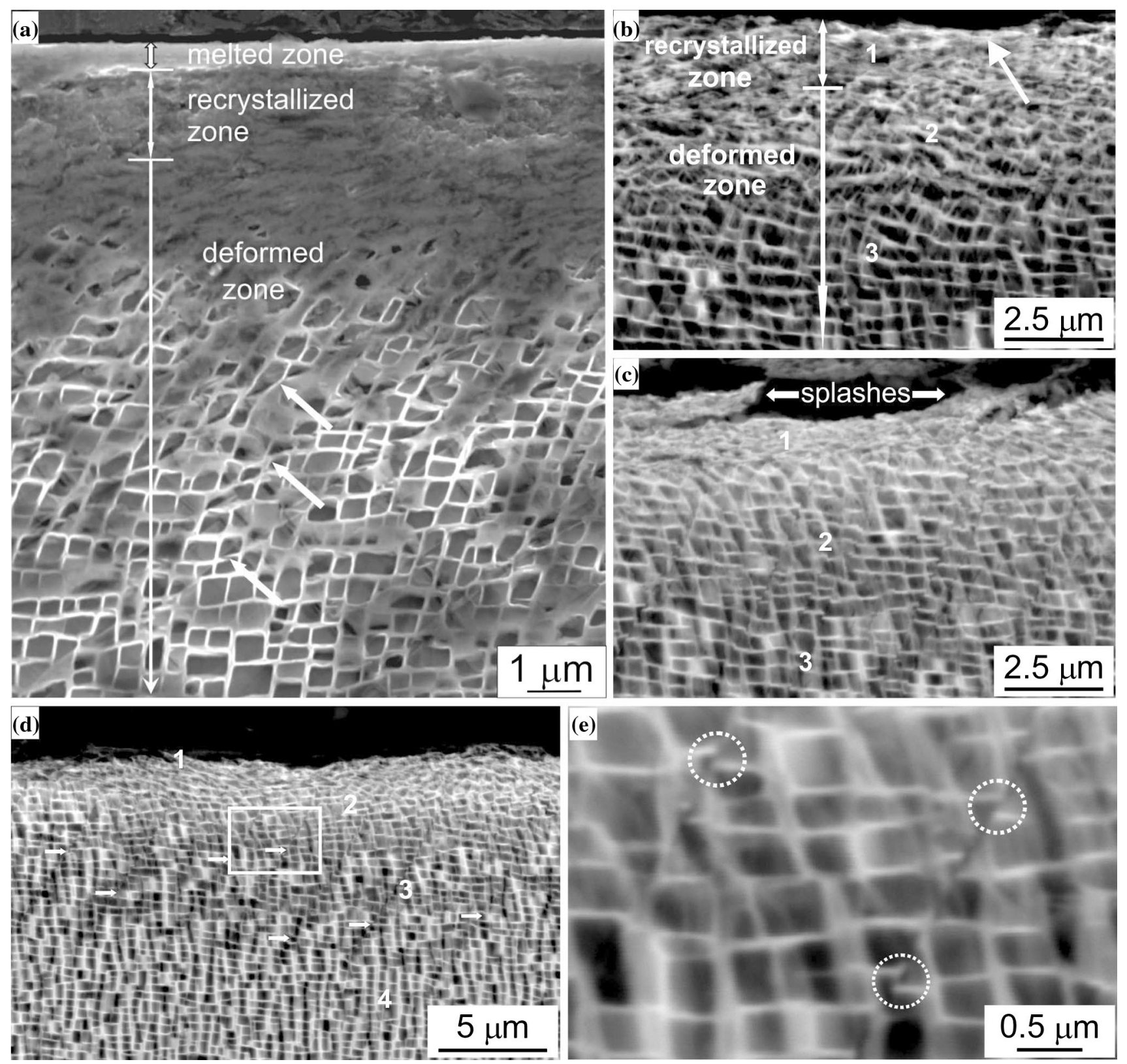

Fig. 5- SEM presenting the microstructure of the surface layer formed in different areas of the laser-shocked spot in the plane perpendicular to the treated surface: $(a)$ in the melted zone, $(b, c$ and $d$ ) in the peripheral area of the laser-shocked spot. (e) Region marked by a rectangle in (d) at higher magnification. Numbers indicate: 1: the recrystallized zone; 2: heavily deformed zone (with narrow $\gamma$ phase channels oriented perpendicular to surface); 3: partially deformed zone (with narrow $\gamma$ phase channels in the vicinity of slip bands, indicated with arrows in (d); 4 : matrix (not affected by LSP).

surface, roughly parallel to the $\langle 001\rangle$ orientation), and therefore $\gamma$ channels are directly extruded. Moreover, they are also reoriented (both $\gamma^{\prime}$ and $\gamma$ phases, Figures 5(b) and (c)). As a result, the SEM image in these areas looks different from that in the non-laser-treated alloy matrix.

Figure 6 presents the schematic view of the multidirectional shock wave expansion in the laser-affected area. The SEM images show the microstructure in the plane perpendicular to the treated surface in three different areas: (a) the left side area, (b) central laser affected area and (c) right side area. In the images taken in the areas (a) and (c), it could be observed that the $\gamma / \gamma^{\prime}$ interfaces are bent in the impact direction. SEM analysis revealed that in the subsurface areas, the regular arrangement of the $\gamma^{\prime}$ and $\gamma$ phases is totally destroyed. This is due to severe plastic deformation induced by the plasma pressure generated during the laser pulse/substrate interaction. It should be emphasized that, as a result of severe plastic deformation, there was a significant distortion of the cuboidal $\gamma^{\prime}$ phase. In the areas near the surface (up to $\sim 5$ to $6 \mu \mathrm{m}$ beneath the surface), 


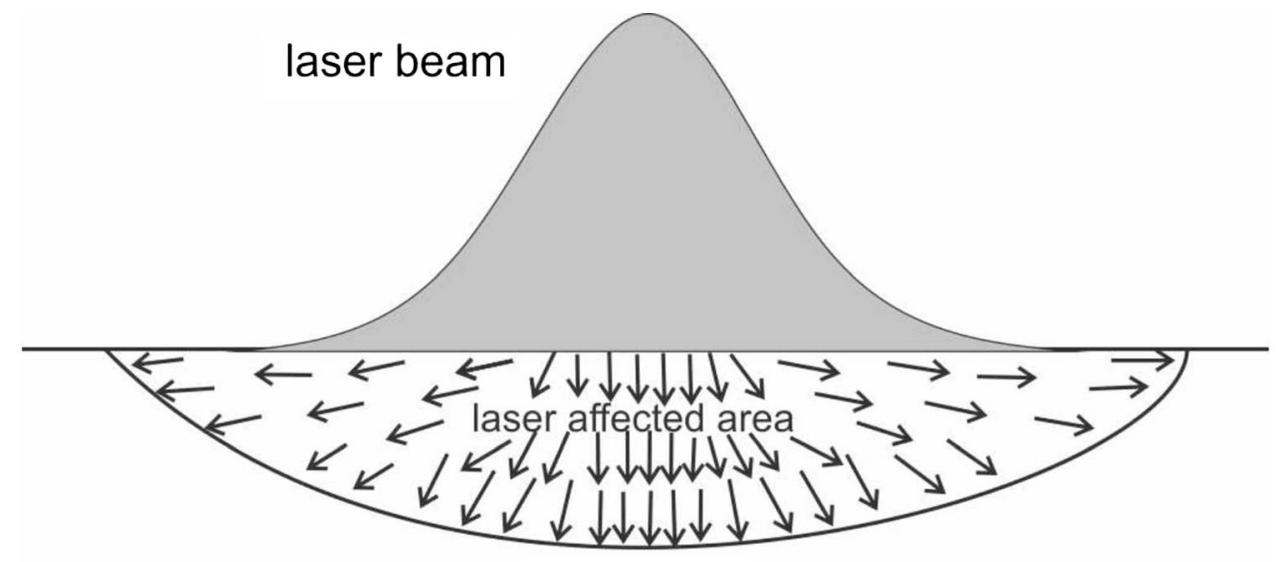

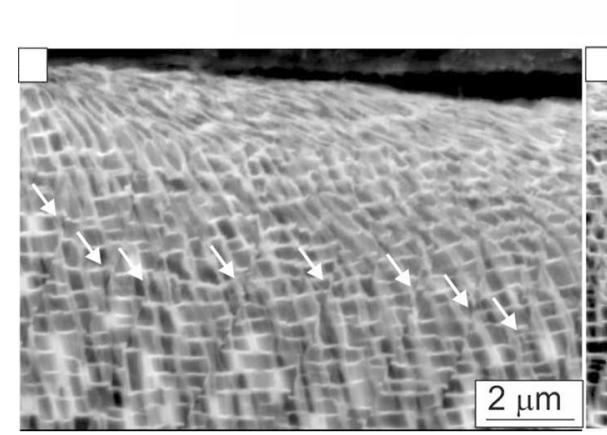

(a)

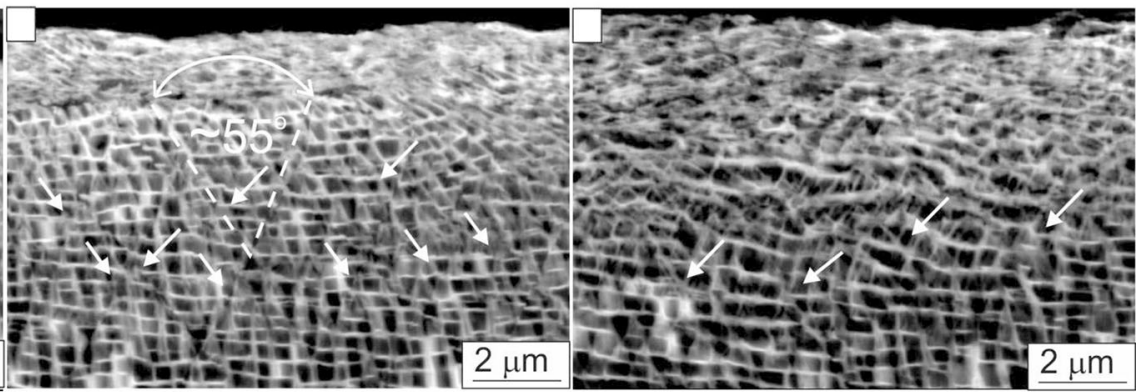

(b) (c)

Fig. 6-Schematic view with arrows showing the shock wave expansion in the laser-affected area illustrated by SEM images of the microstructure in the plane perpendicular to the treated surface; images show the structure in: $(a)$ the left side area, $(b)$ central area and $(c)$ right side area.

they assume diamond-like shapes. The shear bands are indicated with arrows in the SEM images (a), (b) and (c). The shear bands and the $\gamma / \gamma^{\prime}$ interfaces in the image (a) are oriented to the left of the center, while in image (c) to the right of the center of the laser pulse. In image (b) taken in the central part of the laser-affected area, where the greatest deformation occurred, the shear bands run in different directions and are oriented both to the right and to the left of the sample surface. In Figure 6(b), a subsurface zone $(\sim 2 \mu \mathrm{m}$ thick) of the recrystallized material is visible. Electron diffraction analysis (TEM examination) as well an angle of $\sim 55 \mathrm{deg}$ between the slip bands marked in Figure 6 indicates that the shear bands are parallel to $\{111\}$. The laser shock peened specimen experiences an extremely high strain rate $\left(>10^{6} \mathrm{~s}^{-1}\right)$ during a short period of time (10 to $20 \mathrm{~ns}$ ). Moreover, spread of the shock wave in the laser affected area is multidirectional. This could cause other slip systems to operate than those appropriate for the A1 structure $\{111\}\langle 110\rangle$.

Figure 7 shows the microstructure in the left side periphery, $\sim 1.5 \mathrm{~mm}$ from the spot's center. The studies show that, in the $\sim 1$ to $2 \mu \mathrm{m}$ sub-surface zone (encircled as A), the simultaneous interaction of severe plastic deformation and temperature resulted in considerable $\gamma^{\prime}$ and $\gamma$ grain refinement and their alignment. In the areas $\mathrm{B}$ and $\mathrm{C}$, marked with ellipses, a serrated distortion of

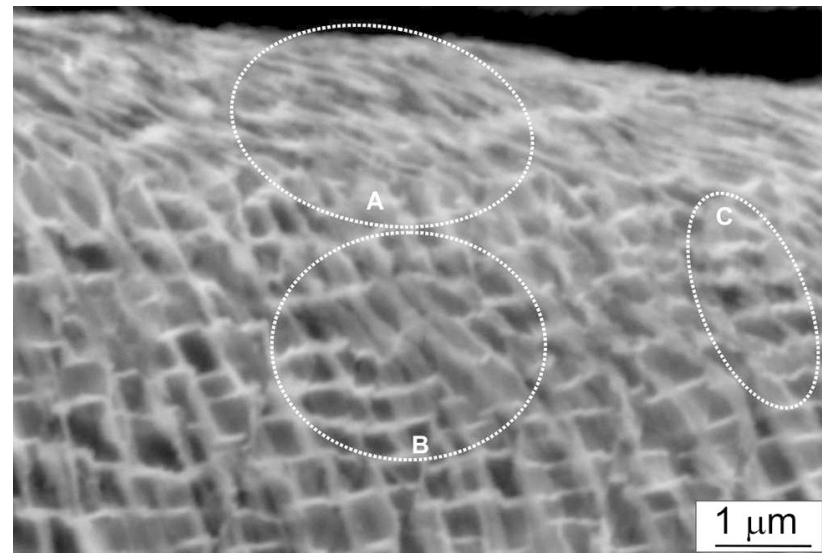

Fig. 7-SEM image shows the microstructure in the left side periphery of the laser-affected area (areas marked with ellipses, showing a serrated distortion of $\gamma / \gamma^{\prime}$ interfaces).

the $\gamma / \gamma^{\prime}$ interfaces (those parallel to the surface) is visible. This type of deformation can be explained using the mechanism proposed by Ting et al. ${ }^{[33]}$ The rhombohedral (diamond-like) shape of $\gamma^{\prime}$ precipitates can be formed during LSP because of multidirectional yielding and the influence of high temperature. As shown by Wen et al., ${ }^{[34]}$ this deformation mode was observed in fractured samples of a nickel-based single-crystal superalloy. In this work, the authors examined the fracture 

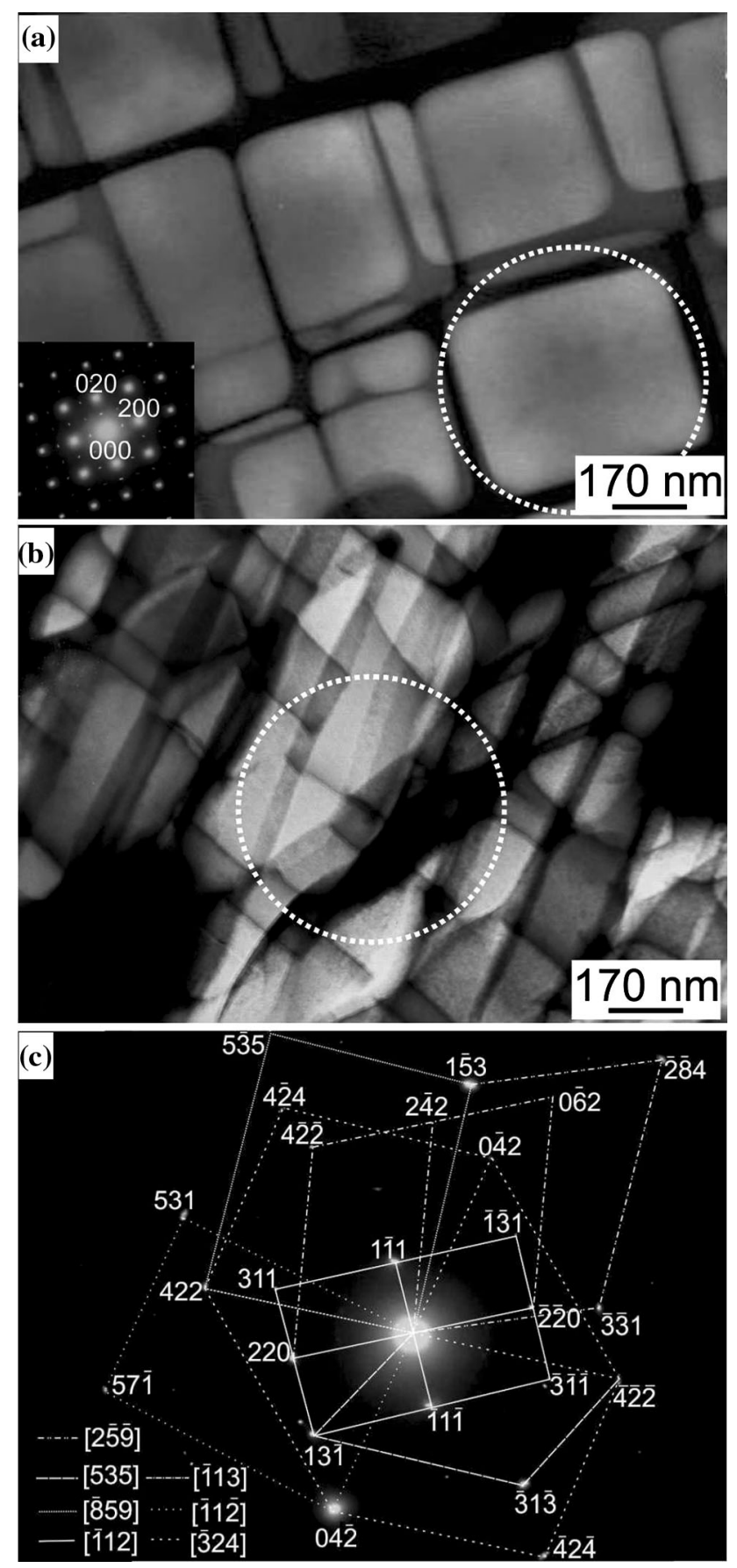

Fig. 8-Plain view TEM images presenting the microstructure for CMSX-4 single-crystal superalloy: $(a)$ substrate (inset is the SAED pattern of the $\gamma^{\prime}$ phase along the [001] zone axis), $(b)$ microstructure of the heavily deformed zone after the LSP experiment; (c) SAED pattern from a few deformed $\gamma^{\prime}$ phase precipitates; circles in micrographs $a$ and $b$ indicate areas in which diffraction was performed.

morphology of notched, nickel-based, single-crystal superalloy specimens with [001], [011] and [111] orientation. Fractured specimens displayed an uneven cleavage configuration with multi-level features and many cleavage planes parallel to the $(001),(011)$ and (111) crystal plane, respectively. The cleavage planes, which are attributed to the cracks propagated along the $\gamma / \gamma^{\prime}$
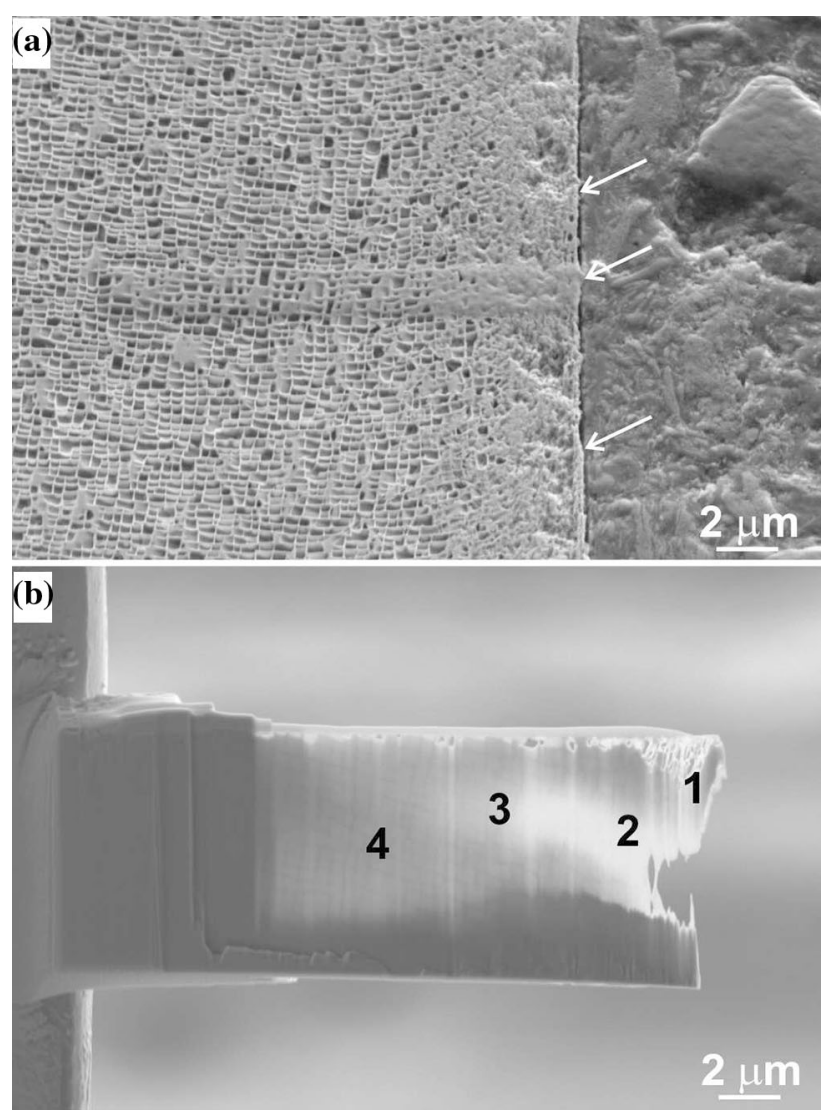

Fig. 9-SEM images $(a$ and $b)$ show two stages of lamella preparation in the LSP deformed surface layer (a: sample surface coated with a platinum bar and b: lamella cut using the FIB technique; arrows indicate a thin melted surface layer), numbers 1 to 4 indicate areas of TEM analysis.

interfaces, displayed square-like, rhombus-like and hexagon-like features, adequate to the sample orientation.

\section{B. TEM and STEM-EDS Examinations}

Figures $8(a)$ and (b) presents the plain view TEM images of the single-crystal CMSX-4 superalloy in the as-fabricated state (Figure 8(a)) and in the highly deformed zone after the LSP (Figure 8(b)). Figure 8(a) shows a typical two-phase $\gamma / \gamma^{\prime}$ microstructure of the CMSX-4 superalloy substrate. After annealing, the $\gamma^{\prime}-\mathrm{Ni}_{3} \mathrm{Al}$ precipitates (average size $\sim 500 \mathrm{~nm}$ ) have a cuboidal shape with unimodal distribution in the $\gamma-\mathrm{Ni}$ matrix. The inset is the SAED pattern of one large $\gamma^{\prime}$ precipitate (encircled in Figure 8(a)) oriented along the [001] zone axis. Figure 8(b) is a TEM plane view image of the highly deformed zone (marked as 2 in Figure 3) after LSP. A distortion of the regular $\gamma / \gamma^{\prime}$ cell structure, in the laser shocked region, as compared to the initial alloy structure (Figure 8(a)), is evident. The SAED pattern in Figure 8(c) of the central part of the image (from the area marked with a circle in Figure 8(b)) represents few differently oriented (probably superimposing), deformed $\gamma / \gamma^{\prime}$ particles. 


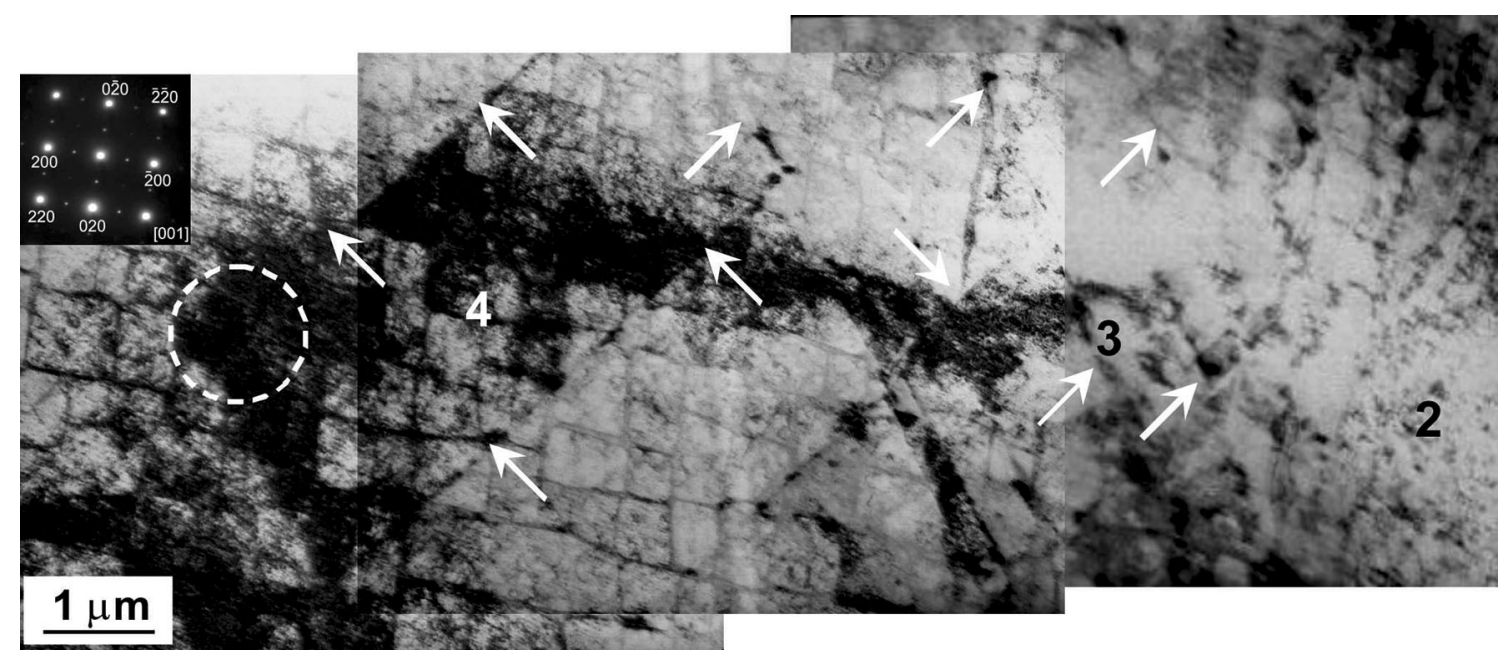

Fig. 10 - Low-magnification TEM image showing the structure of the subsurface deformed layer in zones 2 to 4; arrows indicate slip bands; inset is the SAED pattern registered in the circulated area.
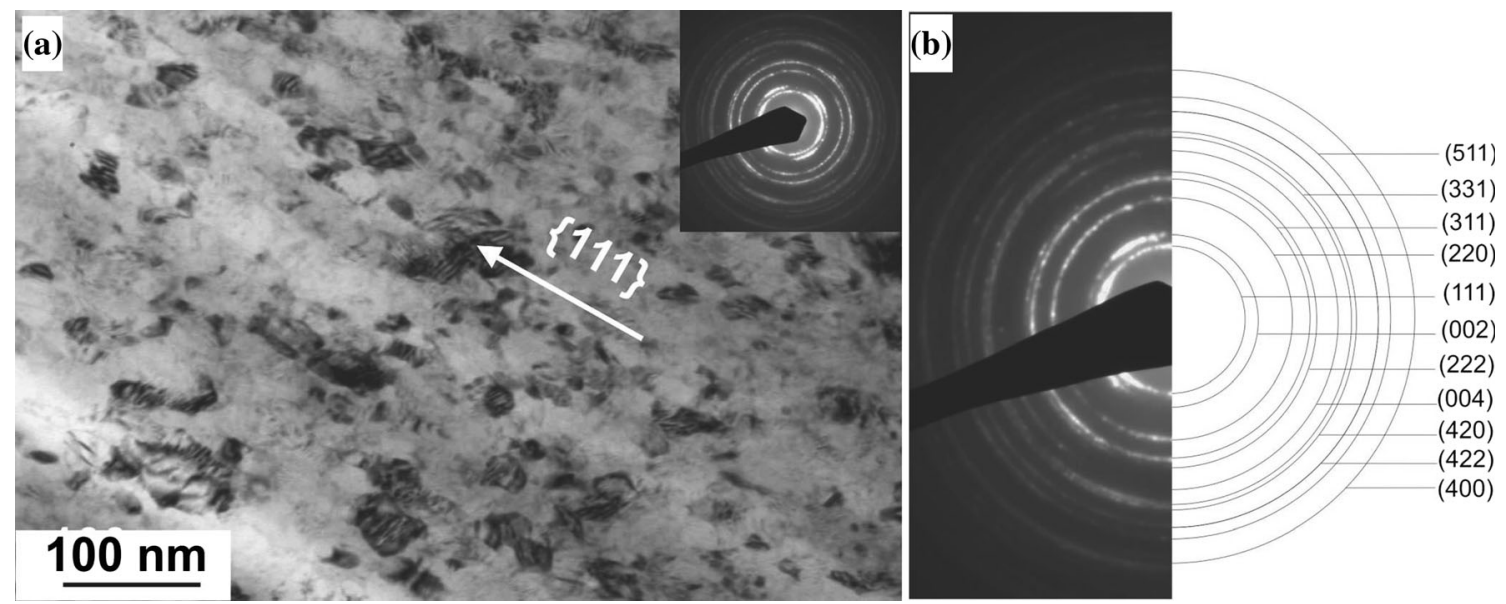

Fig. 11-TEM image (a) shows the nanostructure of the CMSX-4 alloy in the heavily deformed surface zone (in the area marked as 1 in Fig. 9(b)); the inset shows the ring-type SAED pattern characteristic for nanostructures; $(b)$ shows the identified ring pattern of $\gamma / \gamma^{\prime}$ phases.

To analyze in detail the structural changes in the surface layer of the CMXS-4 alloy after LSP, FIB lamellas were cut from the deformed area in a plane perpendicular to the treated surface. Figure 9 shows SEM images of the sample surface coated with a platinum bar [up to $\sim 15 \mu \mathrm{m}$ beneath the surface (Figure 9(a))] and the lamella cut with FIB (Figure 9(b)). The numbers 1 to 4 in Figure 9(b) indicate individual zones on the lamella, in which detailed TEM observations were carried out at a higher magnification. Figure 9(a) clearly shows that right next to the heated surface the sample is porous. Indeed, in these areas, holes are also observed on the cut lamella (SEM image in Figure 9(b)).

Figure 10 shows a typical low-magnification TEM image of the surface layer resulting from a single LSP impact. Arrows in the TEM micrograph indicate slip bands, while the inset is the SAED pattern, which was registered within the circulated area. Image analysis shows that the structure of the surface layer clearly changes along its cross section, from nanocrystalline (right next to the surface, in zone 2), through heavily deformed rhombohedra of $\gamma^{\prime}$ phase (zone 3) to cuboidal $\gamma^{\prime}$ with high dislocation density (zone 4). The deformed surface layer shows numerous shear bands (arrowed) parallel to $\{111\}$, the density of which increase near the sample surface (in zone 3). Analysis of the electron diffraction patterns allows to conclude that the shear bands are parallel to $\{111\}$ (inset in Figure 10).

Figures 11 through 15 are magnified TEM images of the lamella taken in zones 1 to 4 indicated in Figure 9(b). TEM analysis of zone 1 (Figures 11 and 12) indicates that the plastic strain caused by LSP treatment induced grain refinement, with the characteristic ring diffraction pattern of nano-grains present in the area of $\sim 6 \mu \mathrm{m}^{2}$ (see inset and resolved SAED pattern in Figure 11(b)). In this figure, diffraction spots form concentric ring patterns characteristic of a polycrystalline structure. This indicates the presence of an ultrafine structure and high disorientation between 


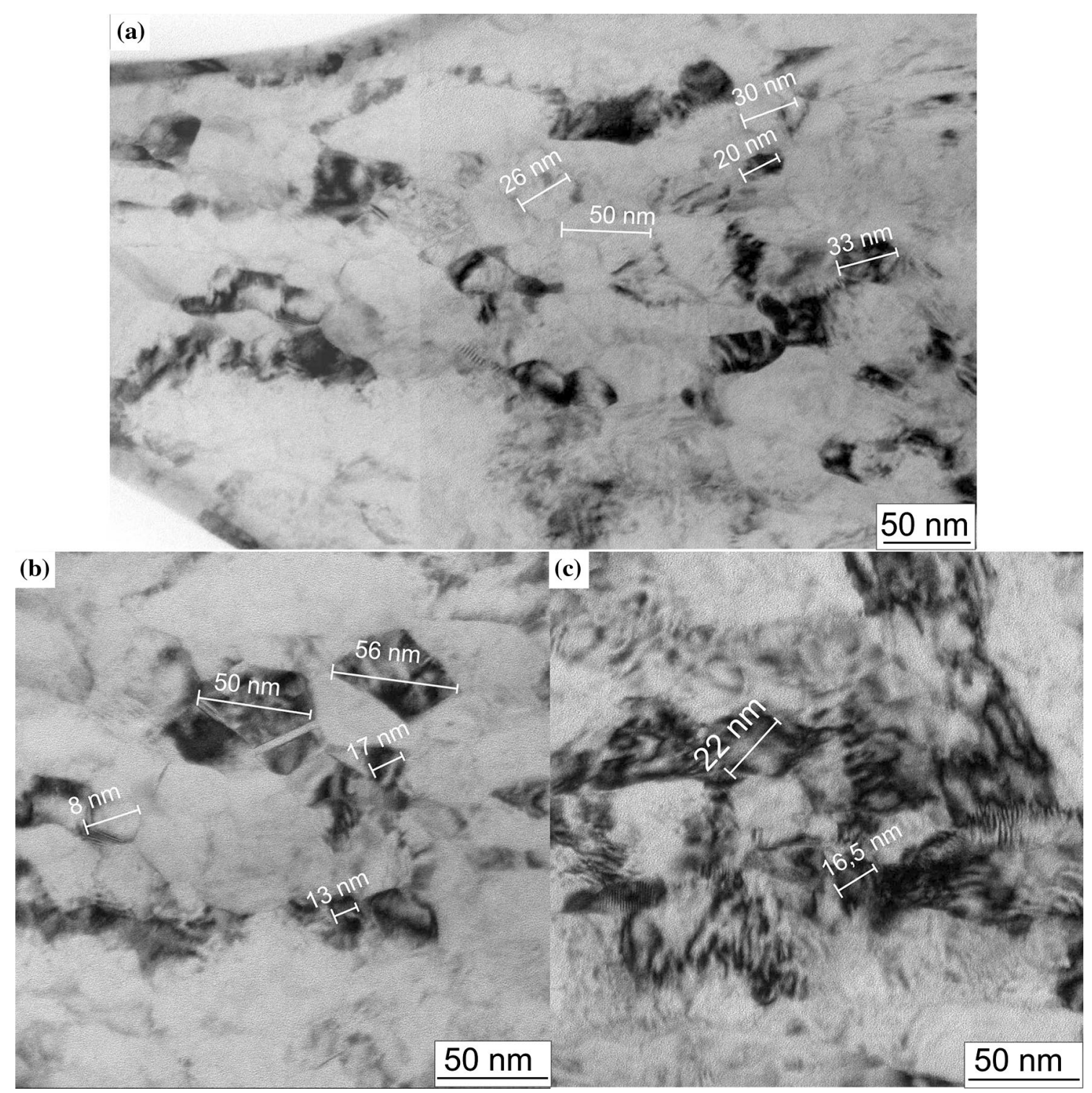

Fig. 12-TEM images showing a recrystallized area located next to the LSP surface: (a) area lying approximately 100 to $300 \mathrm{~nm}$ beneath surface, $(b)$ area 300 to $500 \mathrm{~nm}$ from surface and $(c)$ area 600 to $900 \mathrm{~nm}$ below the surface, where highly strained grains were observed.

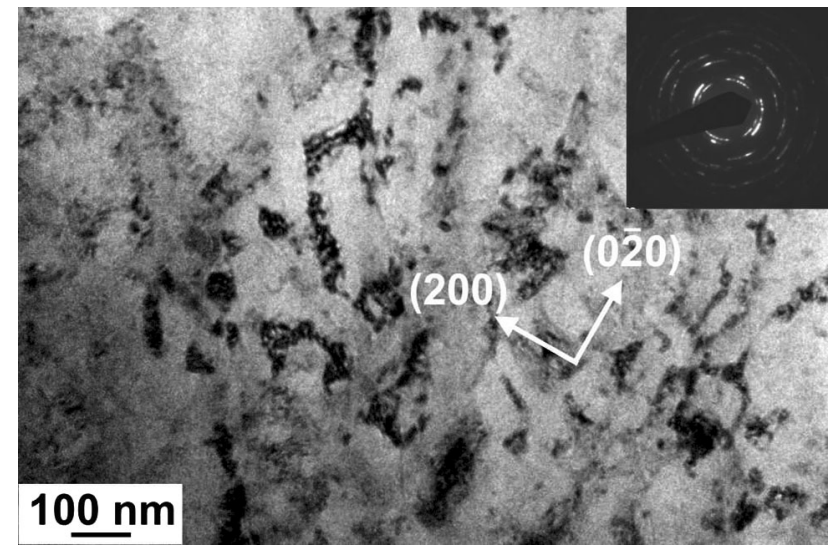

Fig. 13-TEM image shows coarser nanostructure of the CMSX-4 alloy in the deformed surface zone (in the area marked as 2 in Fig. 9(b)). grains. The average size of grains is much smaller than $50 \mathrm{~nm}$. The rings are discontinuous. Some spots have a different brightness and spread, which may suggest a preferred orientation of the grains, an accumulation of dislocations and the existence of lattice distortions.

The grain refinement is attributed to their fragmentation as a result of shearing of the material during LSP. The generation of a high density of dislocations inside these small domains during LSP would lead to fine sub grains and eventually grains with high angle boundaries from the rotation of the subgrains, while the temperature increase could promote the partial recrystallization of the deformed material. The $\gamma^{\prime}$ phase is also susceptible to intensive deformation twinning during plastic deformation. ${ }^{[35]}$ Figures 11 and 12 showing ultrafine grains with a size $<50 \mathrm{~nm}$ readily developed in the near surface zone (zone 1) during LSP. The development of new ultrafine grains in CMSX-4 alloy during large strain 


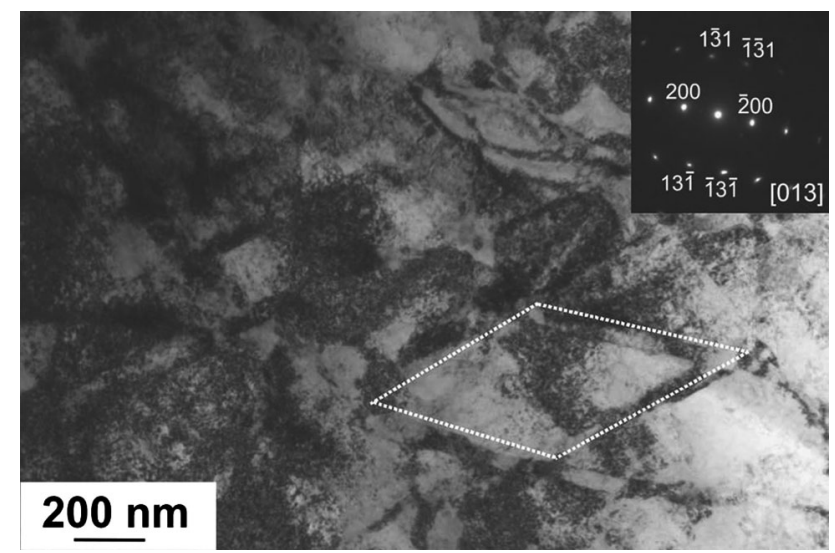

Fig. 14-TEM image shows the structure of the CMSX-4 alloy in the deformed surface zone (in the area marked as 3 in Fig. 9(b)) Note: cuboidal $\gamma^{\prime}$ precipitates deformed to rhombohedral shape (diamond indicated with dotted sides).

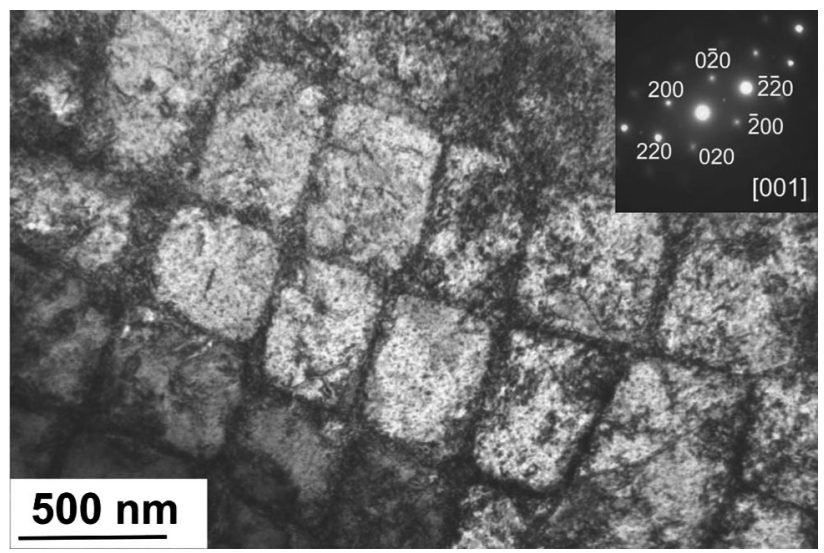

Fig. 15-TEM image showing the microstructure for CMSX-4 in the deformed surface zone (in the area marked as 4 in Fig. 9(b)); inset is the SAED pattern of $\gamma^{\prime}$ phase (two beam condition close to the [001] zone axis)

deformation can be considered a kind of continuous dynamic recrystallization of grains with intersecting deformation micro-twins and/or slip bands. ${ }^{[36]}$

In presented case, it is clear that the thin near surface region is affected by both thermal and mechanical strain caused by the laser pulse. In the central area of the laser beam, where the subsurface zone was most strongly heated, recrystallized grains can be observed. As mentioned, they can arise as a result of recrystallization of highly deformed areas due to the heat transfer back to the water-cooled surface. Some of the grains in this zone are twinned (Figure 12(b)). The grains are $\langle 011\rangle$ oriented and parallel to the sample surface. The average grain size is approximately $30 \pm 5 \mathrm{~nm}$. Figure 12(c) shows the structure of the recrystallized zone in the area lying $\sim 600$ to $900 \mathrm{~nm}$ below the treated surface. The high-strain rate and short duration of the laser pulse play an important role in the formation of refined grains during microplastic deformation by LSP. The grains are highly imperfect in the sense that they were heavily deformed as the plasma expanded. Similarly, Lu et al. ${ }^{[32]}$ showed that LSP impacts, due to the ultra-high strain rate and ultra-short laser pulse, involve grain refinement in ANSI 304 stainless steel.

Figure 13 shows a magnified TEM image of zone 2 in which grains are coarser than in zone 1 (with diameter larger than $100 \mathrm{~nm}$ ). A corresponding diffraction pattern (inset in Figure 13) also indicates that these grains are preferentially oriented. The contrast inside grains is non-homogeneous and often undergoes complex changes. This may indicate a high level of internal stresses and elastic distortions of the crystal lattice. In the surface layer (in zones 1 and 2), LSP caused the formation of a highly disperse structure.

In Figure 14, the microstructure of the zone 3 (lying $\sim 6 \mu \mathrm{m}$ beneath the surface) shows the presence of significant and strong distortions of the cuboidal $\gamma^{\prime}$ crystals. In this zone the cuboidal $\gamma^{\prime}$ precipitates are deformed to a rhombohedral shape (the diamond is indicated with dotted sides). In zone 4 (Figure 15), $\gamma^{\prime}$ particles have the same regular shape as in the matrix (compared with Figure 8(a)), but of high dislocation density. Also, slip bands, aligned in one direction, are present in this zone (Figures 10 and 14).

Figures 16(a) through (c) shows the STEM-HAADF microstructure images of the CMSX-4 surface layer with the corresponding EDS combined maps of elements forming the $\gamma^{\prime}$ phase $(\mathrm{Al}, \mathrm{Ni})$ and the $\gamma$ phase $(\mathrm{Cr}, \mathrm{Co})$. As in the work of Dubiel et al. ${ }^{[37]}$ in our research, we also noted the presence of Co, Cr, Re, Mo and $\mathrm{W}$ in the $\gamma$ phase and $\mathrm{Al}, \mathrm{Ti}$, Ta and $\mathrm{Ni}$ in the $\gamma^{\prime}$ phase. However, to show the influence of LSP on changes in the alloy surface layer, we limited ourselves to only presenting the complex maps of $\mathrm{Cr}+\mathrm{Co}$ and $\mathrm{Al}+\mathrm{Ni}$. The intensity of the $\gamma$ phase in the STEM-HAADF images in Figures 16(a) through (c) is brighter than that of the $\gamma^{\prime}$ phase (this type of image contrast intensity is closely related to the atomic number $Z$ ), since this phase contains $\mathrm{Co}, \mathrm{Cr}$ and other heavy elements while $\gamma^{\prime}$ phase mainly contains Ni and Al. In Figure 16(a) (recorded in zone 3), Co and $\mathrm{Cr}$ are distributed in $\gamma$ phase surrounding the cuboidal $\gamma^{\prime}$ precipitates containing mainly $\mathrm{Ni}$ and Al. Shear of $\gamma$ phase, caused by bands cutting both the $\gamma$ and $\gamma^{\prime}$ phases, is also visible in Figure 16(a). Figure 16(b) shows the STEM-HAADF image and EDS maps recorded in zone 2 (as marked in Figure 9(b)). As shown in Figures 11 and 12, due to severe plastic deformation, the structure is refined and preferentially oriented. Indeed, the $\gamma$ and $\gamma^{\prime}$ phases form isolated channels, well visible in the combined distribution maps of $\mathrm{Al}+\mathrm{Ni}$ and $\mathrm{Cr}+\mathrm{Co}$. Figure $16 \mathrm{c}$ was performed in zone 1, at much higher magnification than those in zones 2 and 3 . The icrostructure in this zone is strongly refined, with the grain size well below $50 \mathrm{~nm}$. Nanograins of $\gamma / \gamma^{\prime}$ phases are arranged in the isolated, nanometric size bands. In fact, the distribution of elements (as shown in the combined maps of $\mathrm{Al}+\mathrm{Ni}$ and $\mathrm{Cr}+\mathrm{Co}$ ) in this area is more homogeneous than in zones 2 and 3 .

From the above, it can be stated that the homogenizing process in the surface layer in zones 1 and 2 results from microstructure refining due to severe deformation but not from diffusion. During the diffusion-controlled process, the $\gamma^{\prime}$ precipitate dissolution can 

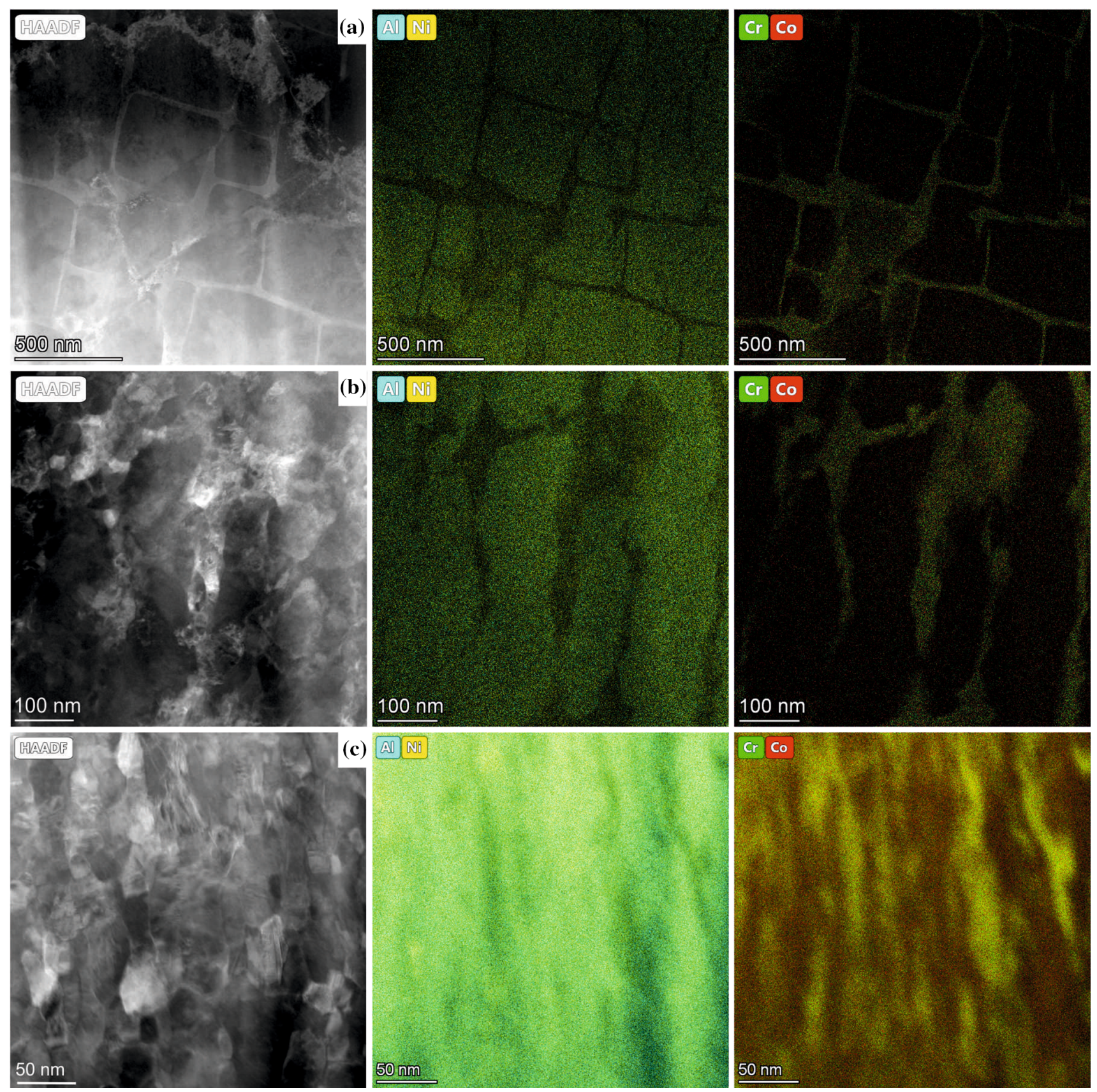

(c) $[$ al]

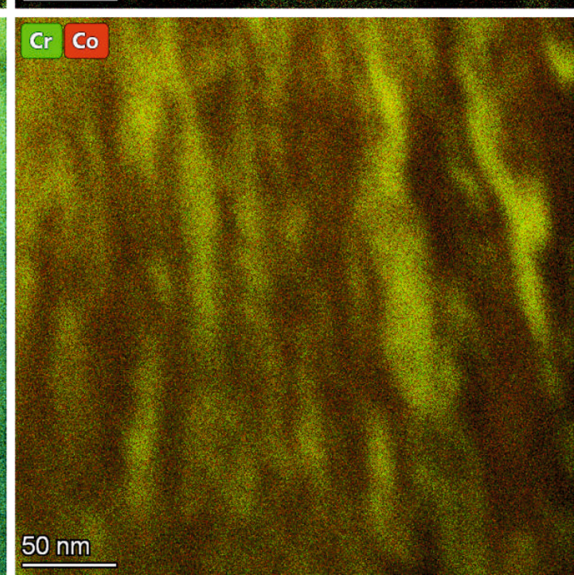

Fig. 16-STEM-HAADF images of CMSX-4 superalloy as deformed by the LSP surface layer (images a-c were recorded adequately in areas $3-1$, as marked in Fig. 9(b)) and EDS combined maps of chemical element distribution in $\gamma^{\prime}(\mathrm{Al}+\mathrm{Ni})$ and $\gamma(\mathrm{Cr}+\mathrm{Co})$ phases. Note: due to structure refinement images and maps were recorded at different magnifications.

be described considering Fick's law as a motion of the precipitate/matrix interface, $x=(D t)^{1 / 2}$. Even at a high temperature range, from $1423 \mathrm{~K}$ to $1623 \mathrm{~K}$, the main CMSX-4 alloy elements, Ni, Al, Cr, Co, W, Ta and Re, have very low diffusion coefficients in $\mathrm{Ni}\left(10^{-13}\right.$ to $\left.10^{-16} \mathrm{~m}^{2} / \mathrm{s}\right) .{ }^{[29]}$ The duration of the LSP is in the order of nanoseconds (18 ns), so redistribution of substitutional elements by diffusion will be negligible. During this ultra-short (ns) time, substitutional atoms practically do not change their places $(x=0.0424 \mathrm{~nm}$, for $D=10^{-15} \mathrm{~cm}^{2} / \mathrm{s}$ and $\left.t=18 \mathrm{~ns}\right)$. This means that during such a short heating time the $\sim 400 \mathrm{~nm}$ precipitates of $\gamma^{\prime}$ phase remain unaffected by diffusion.

\section{Microhardness}

Nanohardness tests were conducted on the cross sections of the LSP-treated samples as well as the untreated material. The nanohardness as a function of the distance from the treated surface is presented in Figure 17. It shows that the laser shock substantially increased the nanohardness of the laser-shocked 


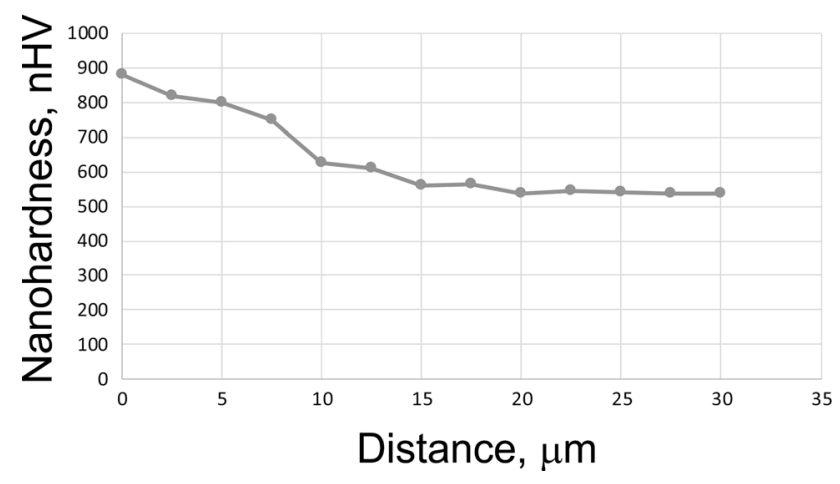

Fig. 17-Nanohardness as a function of distance from the surface.

samples. The nanohardness values of the CMSX4 alloy measured on the polished cross sections without LSP treatment were approximately $530 \pm 3 \mathrm{nHV}$. The laser-treated alloy showed $\sim 40$ pct increase in hardness values as documented in Figure 17. An increase in hardness is probably associated with the grain refinement, high density of dislocations and slip bands generated in the surface region during the LSP. The shock hardening effect decreases gradually with increasing distance from the surface. At a distance of $15 \mu \mathrm{m}$ from the surface, the nanohardness approaches values proper for the core material. A similar trend of hardness increasing after the LSP process was also observed in previous reports on various alloys after laser shock peening. ${ }^{[38]}$ Nath et al.${ }^{[38]}$ examined the influence of laser shock peening on the microstructure, residual stress and hardness of Hastelloy-X superalloys. Using the $10 \mathrm{~J}$ $\mathrm{Nd}$ :YAG laser for the LSP experiments, the authors observed a microhardness increase from 260 to $360-380$ $\mu \mathrm{HV}$ in the $\sim 600-\mu \mathrm{m}$-thick surface layer. They related the increased microhardness to the strain hardening caused by increased dislocation density. It should be emphasized that the authors ${ }^{[38]}$ used the Nd:YAG laser with an energy ten times greater than that used in our experiments; thus, the range of microhardness changes in their case goes much deeper under the surface.

\section{CONCLUSIONS}

The following conclusions may be drawn from the present investigation:

- The microstructure of the surface layer is formed as a result of simultaneous interaction of temperature and compressive stresses involved during LSP.

- Based on the laser-target interactions, three separate heating regimes, depending on the laser beam intensity distribution, the absorption coefficient of the treated material and the thermal diffusion distance, have been identified at the sample surface:

- a melted area covering the central region of the laser affected spots with a diameter of 0.5 to $0.8 \mathrm{~mm}$;

- at the ring area of 0.8 to $1.3 \mathrm{~mm}$, there was a shell of solidified, ejected material;
- the external ring with a diameter of approximately 1.3 to $2 \mathrm{~mm}$, the microstructure was visibly affected by the laser impact.

- Based on the SEM and TEM studies of the sample microstructure, it can be concluded that, depending on the examined spot area subjected to LSP impact, the surface layer consists of:

- three zones: melted, recrystallized and deformed (in the central area of the laser-irradiated dots)

- or

- two zones: recrystallized and deformed (at the peripherals of the laser irradiated dots).

- After LSP experiments, nanograins of $\gamma / \gamma^{\prime}$ phases in the near surface zones are arranged in the isolated, nanometric size bands. In fact, the distribution of elements (as presented in the combined maps of $\mathrm{Al}+\mathrm{Ni}$ and $\mathrm{Cr}+\mathrm{Co}$ ) in this area is much more homogeneous than in the sample core.

- Nanohardness measurements showed an increase in hardness in the superficial surface layer. This could be associated with the high density of dislocations generated in the surface region as well as a high density of slip bands strongly refining the $\gamma / \gamma^{\prime}$ structure.

\section{ACKNOWLEDGMENTS}

The investigation was financed by the AGH University of Science and Technology, Project 16.16.110.663 zad. 1.

\section{OPEN ACCESS}

This article is licensed under a Creative Commons Attribution 4.0 International License, which permits use, sharing, adaptation, distribution and reproduction in any medium or format, as long as you give appropriate credit to the original author(s) and the source, provide a link to the Creative Commons licence, and indicate if changes were made. The images or other third party material in this article are included in the article's Creative Commons licence, unless indicated otherwise in a credit line to the material. If material is not included in the article's Creative Commons licence and your intended use is not permitted by statutory regulation or exceeds the permitted use, you will need to obtain permission directly from the copyright holder. To view a copy of this licence, visit http://creat ivecommons.org/licenses/by/4.0/.

\section{REFERENCES}

1. C. Korner, M. Ramsperger, C. Meid, D. Burger, P. Wollgramm, M. Bartsch, and G. Eggeler: Metall. Mater. Trans. A, 2018, vol. 49A, pp. 3781-92.

2. X. Wu, P. Wollgramm, C. Somsen, A. Dlouhy, A. Kostka, and G. Eggeler: Acta Mater., 2016, vol. 112, pp. 242-60. 
3. A. Kruk, B. Dubiel, and A. Czyrska-Filemonowicz: 2nd European Symposium on Superalloys and their Applications, MATEC Web of Conferences 14, 2014, pp. 1-5.

4. B. Dubiel, P. Indyga, I. Kalemba-Rec, and T. Moskalewicz: Acta PhysPol. A, 2017, vol. 131 (5), pp. 1375-78.

5. M. Kattoura, S.R. Mannava, D. Qjan, and V.K. Vasudevan: Int. J. Fatiqe, 2017, vol. 102, pp. 121-34.

6. C. Chen, X. Zhang, L. Han, and X. Yan: J. Iron Steel Res. Int., 2018, vol. 25, pp. 108-19.

7. B.S. Yilbas, A.F.M. Arif, S.Z. Shuja, M.A. Gondal, and J. Shirokof: J. Mater. Eng. Perform., 2014, vol. 13 (1), pp. 47-54.

8. Y. Li, L. Zhou, W. He, G. He, X. Wang, X. Nie, B. Wang, S. Luo, and Y. Li: Sci. Technol. Adv. Mater, 2013, vol. 14, pp. 1-9.

9. R. Brockman, W. Braisted, S.E. Olson, R.D. Tenaglia, A. Clauer, K. Langer, and M.J. Shepard: Int. J. Fatique, 2012, vol. 36, pp. 96-108.

10. Y.B. Guo, M.P. Sealy, and Ch. Guo: Manuf. Technol., 2012, vol. 61, pp. 583-86.

11. A.S. Gill, A. Telang, and V.K. Vasudevan: J. Mater. Process. Technol., 2015, vol. 225, pp. 463-72.

12. M. Rozmus-Gornikowska, L. Cieniek, and J. Kusinski: J. Mater. Eng. Perform., 2020, vol. 29 (3), pp. 1544-49.

13. W. Zhuang and B. Wicks: J Eng Gas Turbines Power, 2003, vol. 125 (4), pp. 1021-25.

14. M. Rozmus-Gornikowska, J. Kusinski, and M. Blicharski: Arch. Metall. Mater., 2011, vol. 56 (3), pp. 717-21.

15. S.G. Irizalp, N. Saklakoglu, and B.S. Yilbas: Int. J. Adv. Manuf. Technol., 2014, vol. 71, pp. 109-15.

16. Y. Trdan, J.L. Ocana, and J. Grum: Mech. Eng. J., 2011, vol. 57 (5), pp. 385-93.

17. M. Rozmus-Gornikowska, J. Kusinski, and M. Blicharski: Arch. Metall. Mater., 2009, vol. 54 (3), pp. 665-70.

18. M. Rozmus-Gornikowska, J. Kusinski, and M. Blicharski: Arch. Metall. Mater., 2010, vol. 55 (3), pp. 635-39.

19. G.X. Lu, J.D. Liu, H.C. Qiaob, Y.Z. Zhoua, T. Jina, J.B. Zhaob, X.F. Suna, and Z.Q. Hua: Opt. Laser Technol., 2017, vol. 91, pp. 116-19.

20. G.X. Lu, J.D. Liu, H.C. Qiao, T. Jin, and X.F. Sun: Surf. Coat. Technol., 2017, vol. 321, pp. 74-80.

21. F.I. Versnyder and M.E. Shank: Mater. Sci. Eng., 1970, vol. 6, pp. $213-47$.
22. M. Ramsperger, R.F. Singer, and C. Korner: Metall. Mater. Trans. A, 2016, vol. 47A, pp. 1469-80.

23. Z. Shi, J. Li, and S. Liu: Prog. Nat. Sci., 2012, vol. 22 (5), pp. $426-432$

24. J. Hoffman, T. Moscicki, W. Mroz, and Z. Szymanski: Laser-Induced Carbon Plasma; Modeling and Experiment, ESCAMPIG XXI, Viana do Castelo, 2012.

25. T. Moscicki: Int. J. Opt., vol. 2016, pp. 1-13.

26. S. Tan, J. Wu, Y. Zhang, M. Wang, and Y. Ou: Energies, 2018, vol. 11, pp. 1-17.

27. General Information on Element Nickel, www.efunda.com.

28. T. Thorslund, F.-J. Kahlen, and A. Kar: Opt. Lasers Eng., 2003, vol. 39, pp. 51-71.

29. M. Ramsperger, R.F. Singer, and C. Körner: Metall. Mater. Trans. A, 2016, vol. 47A (3), pp. 1469-80.

30. S. Katakam, S. Santhanakrishnan, H. Vora, J.Y. Hwang, R. Banerjee, and N.B. Dahotre: Philos. Magn. Lett., 2012, vol. 11, pp. 617-24.

31. W.M. Steen and J. Mazumder: Laser Material Processing, Springer, London, 2010.

32. J.Z. Lu, K.Y. Luo, Y.K. Zhang, G.F. Sun, Y.Y. Gu, J.Z. Zhou, X.D. Ren, X.C. Zhang, L.F. Zhang, K.M. Chen, C.Y. Cui, Y.F. Jiang, A.X. Feng, and L. Zhang: Acta Mater., 2010, vol. 58, pp. 5354-62.

33. T. Tinga, W.A. Brekelmans, and M.G.D. Geers: Mater. Sci. Eng., 2010, vol. 18, pp. 1-31.

34. Z. Wen, D. Zhang, S. Li, Z. Yue, and J. Gao: J. Alloys Compd., 2017, vol. 692, pp. 301-12.

35. M. Palumbo, D. Baldissin, L. Battezzati, O. Tassa, R. Wunderlich, H.J. Fecht, R. Brooks, and K. Mills: Mater. Sci. Forum, 2006, vol. 508, pp. 591-96.

36. H.U. Hong, B.G. Choi, I.S. Kim, Y.S. Yoo, and C.Y. Jo: Procedia Eng., 2011, vol. 10, pp. 281-86.

37. B. Dubiel, P. Indyka, I. Kalemba-Rec, and T. Moskalewicz: Acta Phys. Pol. A, 2016, vol. 130, pp. 1110-13.

38. S. Nath, P. Shukla, X.-J. Shen, and J. Lawrence: Lasers Eng., 2018, vol. 39, pp. 97-112.

Publisher's Note Springer Nature remains neutral with regard to jurisdictional claims in published maps and institutional affiliations. 